\title{
THERMODYNAMIC AND THERMOPHYSICAL ASSESSMENT OF HYDROCARBONS APPLICATION IN HOUSEHOULD REFRIGERATOR
}

\begin{abstract}
I. M. G. Almeida ${ }^{a}$, ABSTRACT
C. R. F. Barbosa ${ }^{b}$, and F. A. O. Fontes ${ }^{\text {b }}$

${ }^{a}$ Federal Institute of Education, Science and Technology of Rio Grande do Norte Department of Refrigeration Paraíso

CP. 59200-000, Santa Cruz, Rio Grande do Norte, Brazil

igor.almeida@ifrn.edu.br

${ }^{b}$ Federal University of Rio Grande do Norte

Department of Mechanical Engineering Lagoa Nova, S/N, Natal, Rio Grande do Norte, Brazil. cleiton@ufrnet.br franciscofontes@uol.com.br
\end{abstract}

\section{NOMENCLATURE}

COP coefficient of performance

$\mathrm{h} \quad$ specific enthalpy, $\mathrm{kJ} / \mathrm{kg}$

$P \quad$ pressure, $\mathrm{kPa}$

$\mathrm{P}$ power compression, $\mathrm{kW}$

PR pressure ratio

Q cooling capacity, $\mathrm{kW}$

q refrigeration effect, $\mathrm{kJ} / \mathrm{kg}$

$\mathrm{T}$ temperature, ${ }^{\circ} \mathrm{C}$

$\mathrm{v} \quad$ specific volume, $\mathrm{m}^{3} / \mathrm{kg}$

\section{Greek symbols}

П efficiency

\section{Subscripts}

$\begin{array}{ll}1 & \text { compressor inlet } \\ 2 & \text { compressor outlet } \\ 4 & \text { evaporator inlet } \\ 5 & \text { evaporator outlet } \\ \text { cond } & \text { condensation condition } \\ \text { comp } & \text { compressor condition } \\ \text { dis } & \text { compressor discharge } \\ \text { evap } & \text { evaporation condition } \\ \text { is } & \text { isoentropic } \\ \text { r } & \text { refrigerant }\end{array}$

vol volumetric

\section{INTRODUCTION}

In September 2007, when it celebrated 20 years of successes of the Montreal Protocol, a new landmark decision was made by all the signatories of that agreement. With the end of the use of CFC's, in 2010, it was decided by the beginning of the replacement of HCFC's already in 2013, ten years in anticipation of the deadline set by the Montreal Protocol for abandoning the use of these gases. Besides the benefits for the recovery of the ozone layer, the object of the Protocol, the measure also brings a huge benefit for climate regime, given the sharp Global Warming Potential (GWP ) of HCFC 's.

Over its 20 years, the elimination of CFC's that contributed significantly to avoid the issuance of billions of tonnes of $\mathrm{CO}_{2}$ equivalent and may continue to do so with a cost - benefit of more favorable. In Brazil, the anticipation of the deadline for eliminating $\mathrm{CFC}^{\prime} \mathrm{s}$ determined by Resolution CONAMA 267/2000 avoided the consumption of 36,500 tonnes of CFC's, which is equivalent, in its effect to global warming, to 360 million tonnes of $\mathrm{CO}_{2}$. By comparison, national ethanol production, the most successful program of renewable fuels in the world, from 1975 to 2005 
avoided the emission of 650 million tonnes of $\mathrm{CO}_{2}$. Anticipating the time of abandonment of HCFC's will mean further gains.

However, efforts to research and development in the field of Refrigeration and Air - Conditioning apply to the use of natural refrigerants is not only associated with the need to preserve the environment itself, but also has great importance in the latent need for enhanced efficiency energy equipment. Such a feature is observed in Decision XIX/6 of the Montreal Protocol.

In this sense, according to several studies carried out with such fluids, the use of oil operations in the drop -in (replacement process of a refrigerant with no change in the structural components of the refrigerator) in refrigeration provides favorable conditions to reduce consumption energy. Hydrocarbons, such as liquefied petroleum gas (LPG), are environmentally friendly and its products are available in abundance in nature. In this sense, the use of these substances as refrigerants in domestic refrigerators is very attractive. Little information is available in the scientific literature on the use of hydrocarbons in domestic refrigerators. Most work is concentrated on the replacement of CFC-12, and few studies address the replacement of HFC-134a, which is the fluid currently used in such equipment.

Remember that the replacement of HCFC's will be with the introduction of other gases. If the HCFC22 will be replaced mainly by HFC-134a, an alternative more in consolidated market, much of this gain would be nullified, since the GWP of the two substances is similar.

Refrigerators are among the features that represent the largest holdings in residential electricity consumption in Brazil. This contribution is estimated at around $30 \%$ in 2004 representing an approximate electricity consumption of $23,000 \mathrm{GWh}$, about $6.3 \%$ of total electricity consumption in the country. Despite progress in increasing efficiency in energy consumption of refrigerators available in the market, which is indicated by the label PROCEL, there are still operating in many Brazilian residences with older equipment inefficient technologies.

It is estimated that the participation of refrigerators older than 15 years in the stock in use is approximately $12 \%$. This suggests extending the use of equipment with the use of inefficient technologies and efficiently degraded. The use of such equipment may be up to 5 times higher than the new equipment rated seal PROCEL (Jannuzzi and Melo, 2008).

By demonstrating the relationship between emissions CFC's and destruction of the stratospheric ozone layer made by Rowland and Molina in 1974 and the subsequent signing in 1987, the Montreal Protocol in 1987, which imposed targets for the elimination of HCFC's CFC's, the issue of environmental impact of air conditioning and refrigeration industry seemed so resolved. However, the discussion about global warming, which for some time had been gaining strength in the scientific community, turned out to lead in 1997, the signing of the Kyoto protocol, which took on targets for reducing emissions of greenhouse gases (among they HFC 's) by developed countries.

Again, the industrial and scientific community working in the sector of refrigeration and air conditioning world was facing the need to develop a new generation of refrigerants now also committed to preserving the environment.

Richardson and Butterworth (1995) conducted experiments to investigate the performance of hydrocarbons in a hermetic vapor compression refrigeration system. Tests were performed using $\mathrm{R} 12$, propane and mixtures of propane/isobutane composition varying around $50 \% / 50 \%$. The authors found that the mixture of propane / isobutene with composition of $50 \%$ of propane has a higher COP, less charge on the system and lower the wall temperature of the compressor compared to R12.

MacLaine-Cross (1997) showed that the hydrocarbon refrigerants provide $20 \%$ reduction in energy consumption compared to $\mathrm{CFC12}$ and HFC134a.

Kim et al. (1998) evaluated the performance of hydrocarbon refrigerant R600a as an alternative to $\mathrm{R} 12$ in an automatic defrost domestic refrigerator of 215 liters of capacity. The authors developed a theoretical analysis using the software REFPROP, cycle-based vapor compression refrigeration ASHRAE standard, and then conducted a series of tests with the R600a. For the tests only the compressor and capillary tube were modified equipment. The tests were conducted under controlled conditions of temperature and relative humidity $\left(30^{\circ} \mathrm{C}\right.$ and $75 \%$ respectively).

Alsaad and Hammad (1998) examined the use of liquefied petroleum gas (LPG ) with $24.4 \%$ of R290, R600 of $56.4 \%$ and $17.2 \%$ of R600a as a refrigerant for drop-in domestic refrigerators with R12. The authors reported an evaporator temperature of $-15^{\circ} \mathrm{C}$ and 3.4 coefficient of performance for a condensing temperature of $27^{\circ} \mathrm{C}$ when LPG is used.

Hammad and Alsaad (1999) investigated the performance parameters of household refrigerator unmodified when R290 (100\%), R290/R600/R600a (75/19.1/5.9\%), R290/R600/R600a (50/38.3/11.7\%) or R290/R600/R600a (25/57.5/17.5\%) are used as possible replacement alternatives to R12. The authors showed that the mixture of hydrocarbons with $\mathrm{R} 290 / \mathrm{R} 600 / \mathrm{R} 600 \mathrm{a}(50 / 38.3 / 11.7 \%)$ is the best alternative refrigerant.

Tashtoush et al. (2002) presented an experimental study on the performance of domestic refrigerators vapor compression with new blends of hydrocarbon/hydrofluorocarbon as refrigerant for replacement of $\mathrm{CFC12}$. The results showed that the mixture of R600, R290 and HFC134a has an excellent performance. 
Lee and $\mathrm{Su}$ (2002) conducted an experimental study in the use of isobutane in a household refrigerator. The results showed that the coefficient of performance was comparable with that obtained by $\mathrm{CFC} 12$ and HCFC22 when used as refrigerants.

Akash and Said (2003) reported that LPG has better performance than the R12. The results showed that a load of $80 \mathrm{~g}$ of LPG had the best results when used in the same refrigerator.

Sekhar et al. (2004) investigated the mixture of HFC134a/hydrocarbons in two systems of low temperature (household refrigerator and freezer) and two medium-temperature systems (vending machine and bottle cooler). The authors concluded that a mixture containing $9 \%$ of hydrocarbon mixtures (mass) has the best performance, resulting in 10-30\% and $5-15 \%$ reduction in energy consumption in systems of medium and low temperature, respectively.

Fatouh and El Kafafy (2006) evaluated theoretically a mixture of hydrocarbons composed of $60 \%$ and $40 \% \mathrm{R} 290 / \mathrm{R} 600$ as a better drop-in replacement for domestic refrigerators based on HFC -134a under abnormal weather conditions, subtropical and tropical regions.

Mohanraj et al. (2007) presented experimental results of the energy efficient hydrocarbons mixture consisting of $45 \%$ HC290 (propane) and 55\% HC600a (isobutane) as drop-in replacement for the HFC134a under various loads (40 g, 50 g, 70 g, 90 g) in a household refrigerator of 165 liters (class tropical) using synthetic oil as a lubricant and R134a $(100 \mathrm{~g})$. Tests were performed at room temperature of $30^{\circ} \mathrm{C}$, without thermal load and the refrigerator door closed as ISO 8187. The results showed that the load of $70 \mathrm{~g}$ of the hydrocarbon mixture has a better COP, lower power consumption, lower pulldown and low temperature discharge in relation to the R134a and the equipment need not change.

Jwo et al. (2009) presented lower pulldown times in the freezer compartment for the R290/R600a (50:50) about $25 \%$ lower than R134a in a domestic refrigerator of 440 liter capacity with forced convection evaporator. These results were obtained with a charge of R290/R600a 40\% less than the charge for R134a and without changes in the mechanical components of the equipment.

An theoretical analysis was developed for R134a, propane (R290) and selected mixtures (R290/R600a $60 \% / 40 \%$, R290/R600a/R134a 40\%/ $30 \%$ / $30 \%$ and R600a/R290 50\%/50\%) in the ASHRAE standard refrigeration cycle (evaporation temperature: $-23.3^{\circ} \mathrm{C}$, condensation temperature: $54.4^{\circ} \mathrm{C}$, temperature of liquid and suction: $32.2^{\circ} \mathrm{C}$ ) using the thermodynamic properties of REFPROP 6.0 , as recommended by Kim et al. (1998).

\section{THEORETICAL MODEL}

First we have developed a theoreticalcomputational analysis of the cooling system proposed in order to obtain estimates of the process of system operation as well as its performance. For this analysis we used dedicated software, namely REFPROP 6.0 (McLinden et al., 1998), for evaluation of thermodynamic and thermophysical properties of refrigerants.

A theoretical analysis was implemented for the use of R134a, propane (R290) and selected mixtures of R290/R600a $60 \%$ / 40 \%, R290/R600a/R134a 40 $\% / 30 \% / 30 \%$ and $\mathrm{R} 290 / \mathrm{R} 600 \mathrm{a} 50 \% / 50 \%$ in the ASHRAE standard cycle cooling (evaporation temperature: $-23.3^{\circ} \mathrm{C}$, condensation temperature: $54.4^{\circ} \mathrm{C}$, temperature of liquid and suction: $32.2^{\circ} \mathrm{C}$ ) using the thermodynamic properties of REFPROP 6.0 , as recommended by Kim et al. (1998). The coefficient of performance of systems for commercial and domestic refrigeration is increased from 10 to $20 \%$ when using mixtures of hydrocarbons containing R600a and R290 (Sekhar et al., 2004).

In order to simulate the vapor-compression refrigerator some assumptions are necessary. These are: a) steady state operation, b) no pressure loss occurs in the pipes, that is, pressure changes occur only at the compressor and capillary tube, c) gains or losses of heat are neglected; d) compressor presents ideal volumetric efficiency and ideal isentropic efficiency of $75 \%$ (Fatouh and El Kafafy, 2006). Figure 1 shows the thermodynamic cycle model used in theoretical and computational analysis.

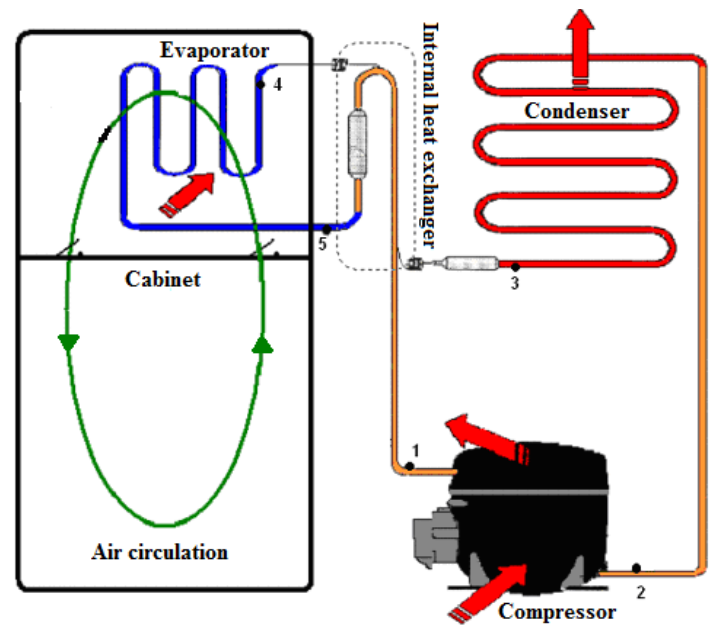

Figure 1. Real thermodynamic cycle of a household refrigerator. (Borges et al., 2010)

For drop-in acceptance of a working fluid in a refrigeration system that already exists, some important performance characteristics should be considered. These are: operating pressure, volumetric cooling capacity, coefficient of performance and compressor discharge temperature (Fatouh and El Kafafy, 2006).

The refrigerant must have a minimum number of essential characteristics favorable, among which the 
most significant are: low density in the liquid phase, high latent heat of vaporization, low specific volume in the vapor phase and low specific heat in the liquid phase. These characteristics will be evaluated and compared between the fluids in question, as recommended by Poggi et al. (2008).

The volumetric cooling capacity $\left(\mathrm{Q}_{\mathrm{vol}}\right)$ is a measure of the compressor size for required operating conditions. Expresses the effect of cooling obtained per $1 \mathrm{~m}^{3}$ of refrigerant entering in compressor (Poggi et al., 2008). It should be noted that, as the volumetric cooling capacity increases, the size of compressor required is reduced. The volumetric cooling capacity $\left(Q_{\mathrm{vol}}\right)$ can be estimated as follows

$$
Q_{v o l}=\frac{\left(h_{5}-h_{4}\right) \cdot \eta_{\text {vol,ideal }}}{v_{1}}
$$

where $h_{5}$ and $v_{1}$ are respectively the specific enthalpy and saturated vapor specific volume condition at the compressor inlet and $\mathrm{h}_{4}$ is the enthalpy specific to the refrigerant entering in evaporator, according with Fig 1. The pressure ratio (PR) is defined as the ratio between the condensation pressure $\left(\mathrm{P}_{\text {cond }}\right)$ and evaporation pressure $\left(\mathrm{P}_{\text {evap }}\right)$, e.g.

$$
P R=\frac{P_{\text {cond }}}{P_{\text {evap }}}
$$

The condensation and evaporation pressures are determined according to the condensation and evaporation temperatures, respectively.

The coefficient of performance (COP) relates the cooling capacity and power required and indicates the overall power consumption for a desired load. High COP means low energy consumption for absorption of the same cooling capacity of space to be refrigerated. Can be expressed as

$$
C O P=\frac{Q_{\text {evap }}}{P_{\text {comp }}}
$$

where $\mathrm{Q}_{\text {evap }}$ is the cooling capacity and $\mathrm{P}_{\text {comp }}$ is power required to drive compressor. The energy balance in the evaporator results

$$
Q_{\text {evap }}=m_{r} \cdot\left(h_{5}-h_{4}\right)
$$

The power required to drive the compressor can be described as

$$
P_{\text {comp }}=m_{r} \cdot\left(h_{2}-h_{1}\right)
$$

The real specific enthalpy of superheated refrigerant vapor leaving to the compressor $\left(h_{2}\right)$ can be calculated as follows

$$
h_{2}=h_{1}+\frac{\left(h_{2, i s}-h_{1}\right)}{\eta_{i s, c o m p}}
$$

where $\eta_{i s, c o m p}$ is the isoentropic efficiency of compressor and $\mathrm{h}_{2 \text {,is }}$ is the specific enthalpy of superheated vapor refrigerant leaving to the compressor for isoentropic compression process.

The refrigerant mass flow $\left(\mathrm{m}_{\mathrm{r}}\right)$ can be estimated using the following equation (Tashtoush et al., 2002)

$$
m_{r}=\frac{Q_{\text {evap }}}{q_{\text {evap }}}
$$

where $\mathrm{Q}_{\text {evap }}$ is the cooling capacity in $\mathrm{kW}$ and $\mathrm{q}_{\text {evap }}$ is the specific cooling effect in $\mathrm{kJ} / \mathrm{kg}$. The mass flow in computer simulation are given in $\mathrm{kg} / \mathrm{h}$.

The compressor discharge temperature $\left(T_{2}=T_{\text {dis }}\right)$ is an important parameter, because its effect on the compressor components and the stability of lubricants. This temperature was determined using both data and condensation pressure and real specific enthalpy at the outlet of the compressor, determined by Eq. (6).

In the cycle analysis, the same cooling capacity was applied to all simulations of refrigerants considered. The cycle cooling capacity of $143 \mathrm{~W}$ was obtained by conversion of freezing capacity (3.5 $\mathrm{kg} / 24 \mathrm{~h}$ ) of a $210 \mathrm{~L}$ household refrigerator, provided by the manufacturer.

\section{RESULTS AND DISCUSSIONS}

Applying the various equations in cooling circuit showned in Fig.1 under predetermined conditions of operation (ASHRAE cycle) and using software REFPROP 6.0 (McLinden et al., 1998) were obtained operating data relating to selected refrigerants. Table 1 shows these results.

Figure 2 presents that the vapor density of the $\mathrm{R} 290 / \mathrm{R} 600 \mathrm{a}$ (50:50) is lower for the whole range of operating temperatures, and thus an expected reduction in the work of compression required. The reduction in density is a more important factor than the latent heat of vaporization of the fluid (Poggi et al., 2008). The decrease of R134a in the mixture leads to a reduction in power required for compression and the heat transfer in condenser. The mixture of hydrocarbons with R134a provides an increase in lubricity and miscibility of the oil with R134a (Tashtoush et al., 2002).

The vapour densities under the suction conditions of the mixtures and R290 presents smaller than those of R134a, corresponding to a less fluid charge required in the system in relation to $\mathrm{R} 134 \mathrm{a}$ (Sekhar et al., 2004). 


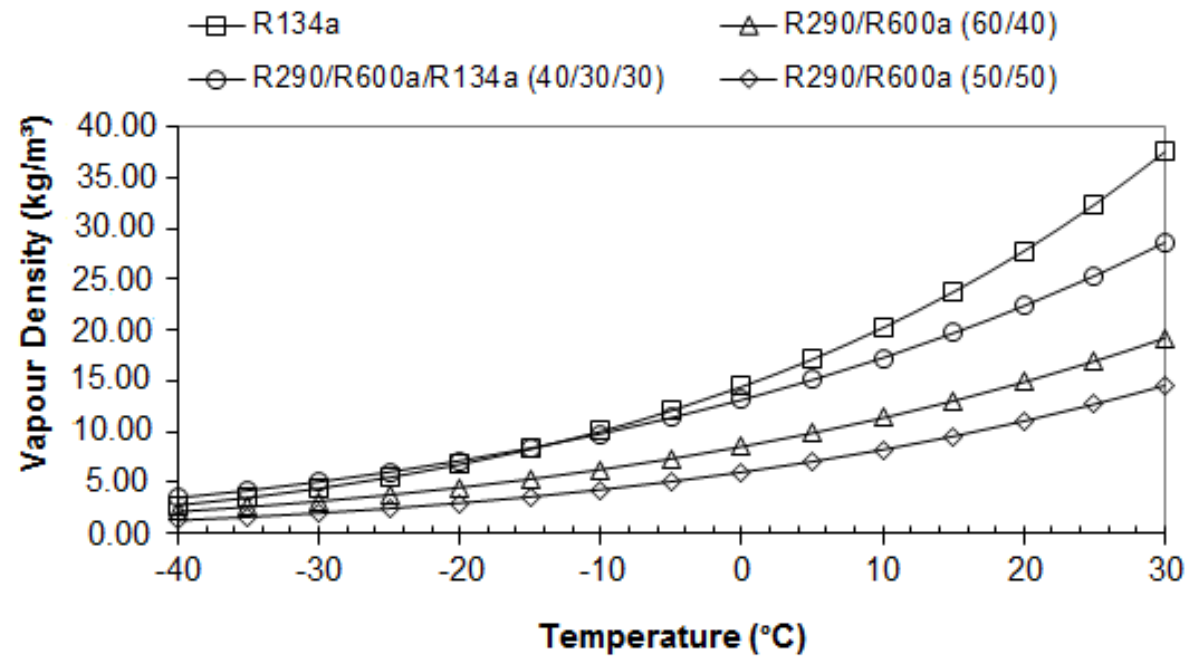

Figure 2. Vapour densities variation relative to temperature.

According to figure 3, the R290/R600a (50:50) and R290/R600a (60:40) gives the lowest liquid densities, providing thereby reducing frictional losses in the system (Sekhar et al., 2004).

In any refrigeration system an portion of lubricating oil circulating with the refrigerant by the various components of the system. The oil effects is strongly correlated with the ability to dissolve the refrigerant in the lubricant. High levels of refrigerant solubility lead to reductions in viscosity of the refrigerant/lubricant, which is beneficial for the oil return to the compressor, but can act over the bearing lubrication.

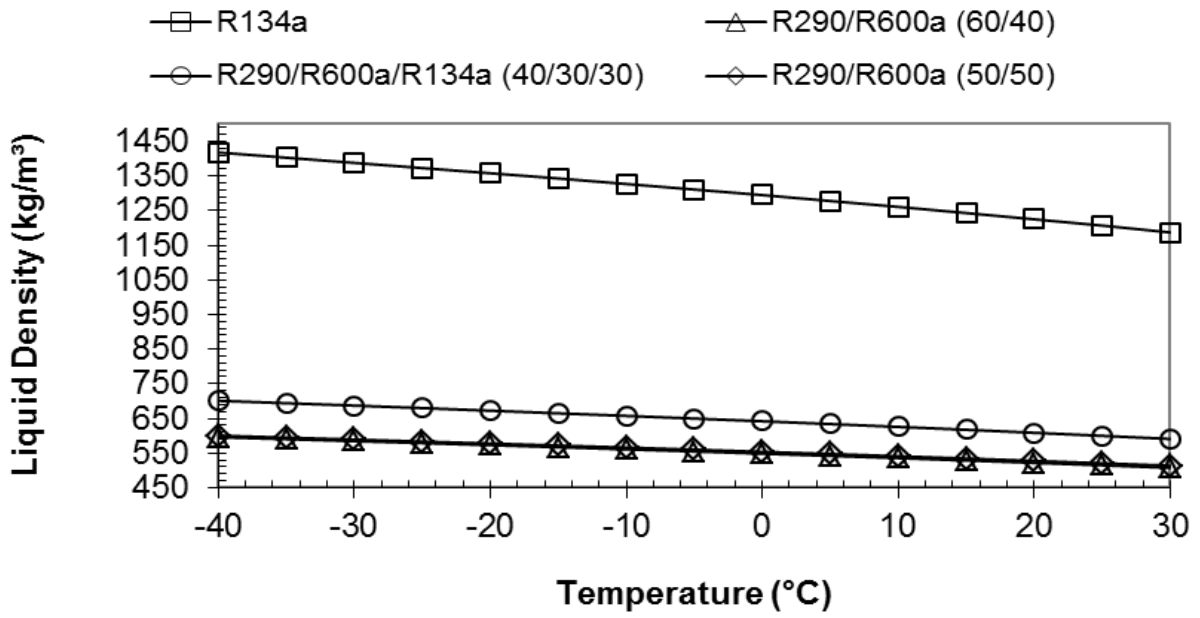

Figure 3. Liquid densities variation relative to temperature.

Figure 4 shows the characteristics of the refrigerants viscosity with different temperatures, it is observed that the R290/R600a (60:40) and R290/R600a (50:50) had the lowest viscosity values across the temperature range temperature. This provides a reduction of pressure losses in the pipes of the refrigeration circuit. 


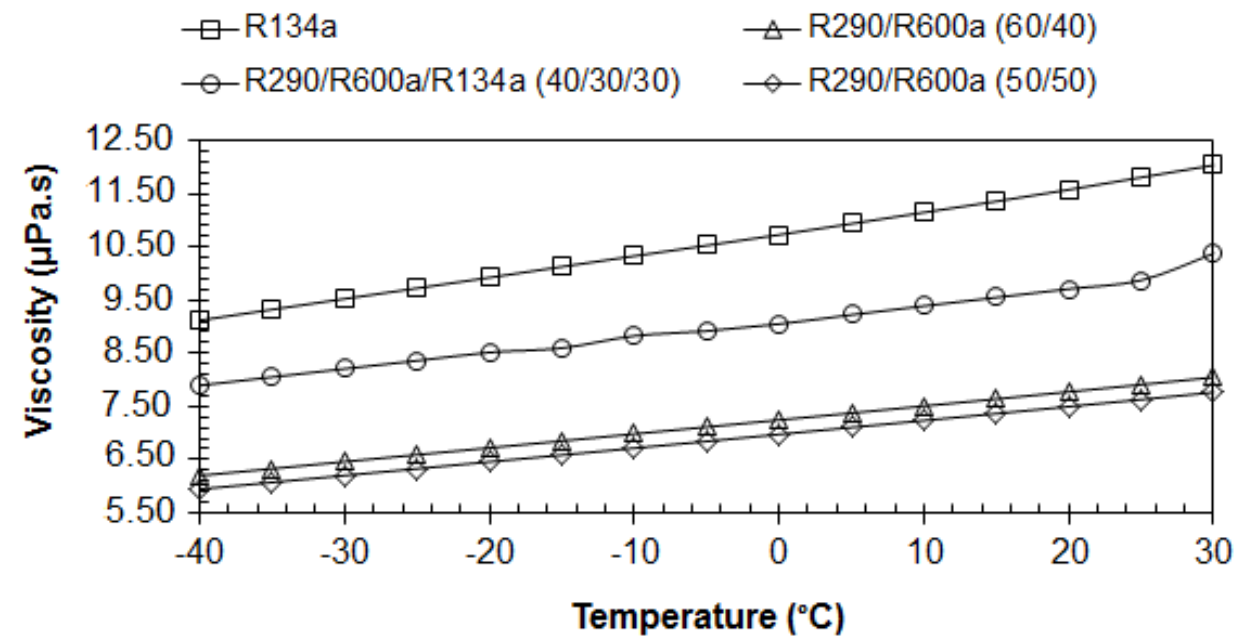

Figure 4. Viscosity variation relative to temperature.

Figure 5 shows the variation in the suction specific volume conditions (suction temperature) of the compressor. It is observed that higher values of specific volume in the compressor suction provides a higher volumetric cooling capacity, resulting in the need for higher displacement of the compressor to the same cooling capacity of the system. It is observed that in order to carry out a drop-in of refrigeration system, the substitute fluid must have similar volumetric cooling capacity to the original fluid so as not to be necessary to replace the compressor. In this regard, it is observed that the R290/R600a (50:50) shows the highest specific volume. The R290/R600a (60:40) had values closer to R134a.

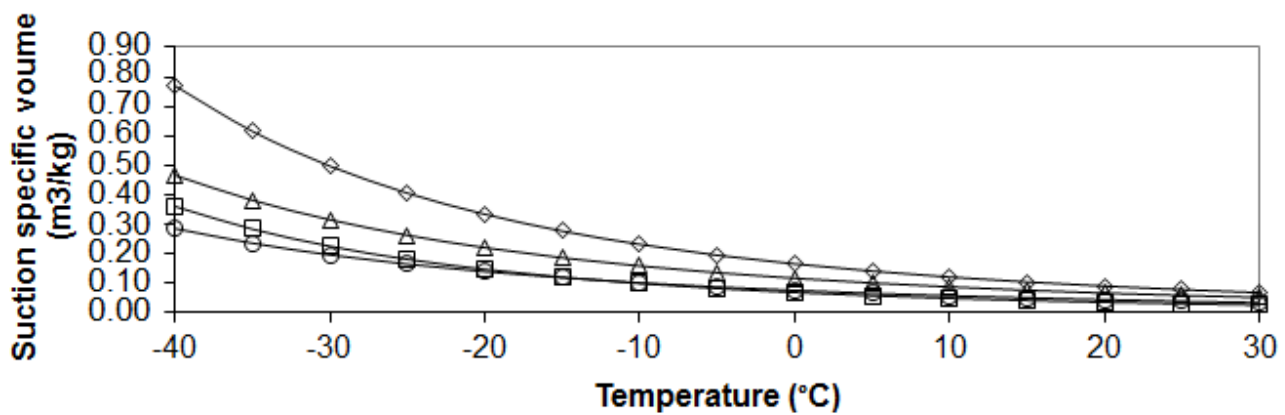

Figure 5. Compressor suction specific volume variation relative to temperature.

Figures 6 and 7 shows the vapour and liquid thermal conductivity of various refrigerants examined as a function of temperature. It is observed that R134a has the lowest conductivity throughout the temperature range. As the fraction of $\mathrm{R} 134 \mathrm{a}$ is reduced, these values increase. The R290/R600a (60:40) and (50:50) have higher conductivity throughout the temperature range, which are substantially equal between the two mixtures. This fact provides a higher heat transfer rates to the refrigeration system. Table 1 presents the numerical results. 


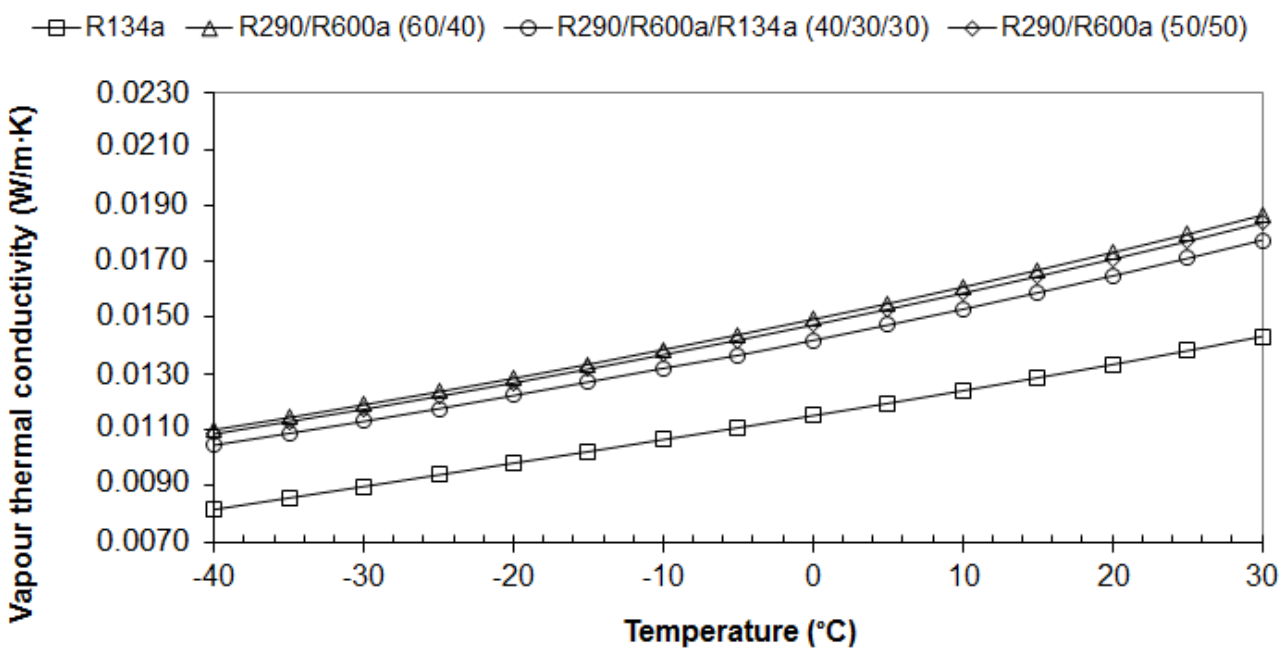

Figure 6. Vapour thermal conductivity variation relative to temperature.

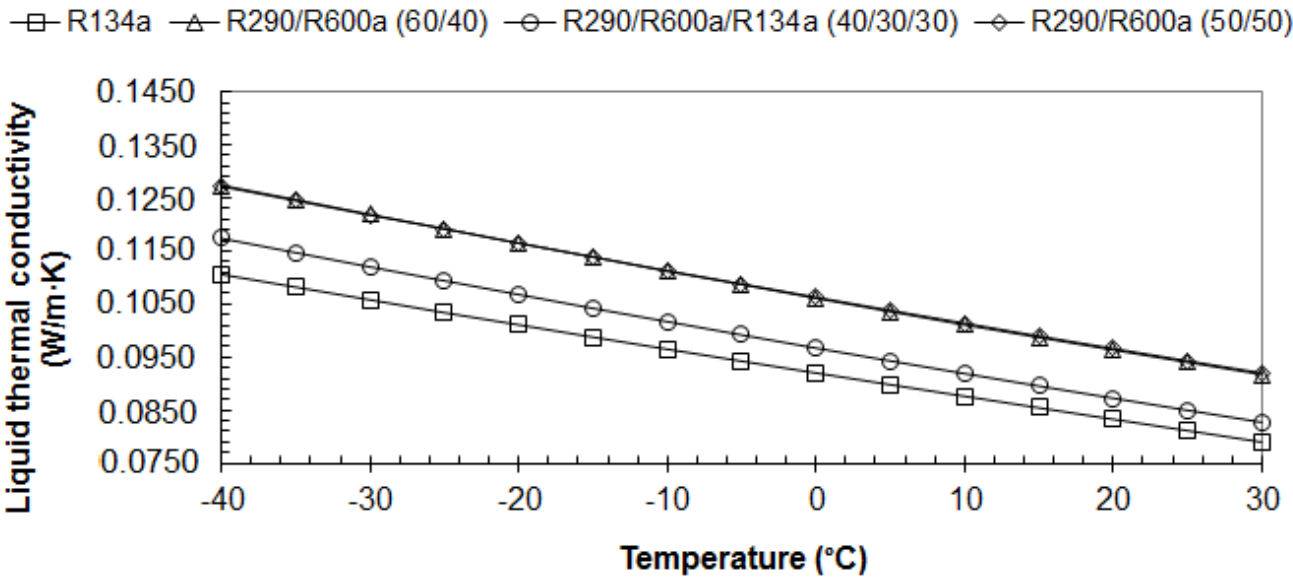

Figure 7. Liquid thermal conductivity variation relative to temperature.

Table 1. Refrigerants computational parameters of ASHRAE cycle.

\begin{tabular}{|c|c|c|c|c|c|c|}
\hline Refrigerant & R134a & R290 & R600a & $\begin{array}{c}\text { R290/R600a } \\
(60: 40)\end{array}$ & $\begin{array}{c}\text { R290/R600a } \\
(50: 50)\end{array}$ & $\begin{array}{c}\text { R290/R600a/R134a } \\
(40: 30: 30)\end{array}$ \\
\hline $\begin{array}{c}\text { Condensation } \\
\text { pressure @ } \\
54.4^{\circ} \mathrm{C}(\mathrm{kPa})\end{array}$ & 1470.0 & 1883.0 & 761.3 & 1370.5 & 1259.0 & 1604.0 \\
\hline $\begin{array}{c}\text { Evaporation } \\
\text { pressure @ - } \\
23.3^{\circ} \mathrm{C}(\mathrm{kPa})\end{array}$ & 114.8 & 216.6 & 62.43 & 140.6 & 126.3 & 174.7 \\
\hline $\begin{array}{c}\text { Pressure } \\
\text { difference } \\
(\mathrm{kPa})\end{array}$ & 1355.2 & 1666.4 & 698.87 & 1229.9 & 1132.7 & 1429.3 \\
\hline Pressure ratio & 12.80 & 8.70 & 12.19 & 9.74 & 9.96 & 9.18 \\
\hline \begin{tabular}{c} 
Refrigeration \\
\hline
\end{tabular} & & & & & & \\
\hline
\end{tabular}




\begin{tabular}{|c|c|c|c|c|c|c|}
\hline effect $(\mathrm{kJ} / \mathrm{kg})$ & 185.58 & 354.47 & 335.90 & 347.85 & 345.90 & 279.70 \\
\hline $\begin{array}{l}\text { Volumetric } \\
\text { cooling } \\
\text { capacity } \\
\left(\mathrm{kJ} / \mathrm{m}^{3}\right)\end{array}$ & 743.719 & 1171.91 & 414.149 & 819.718 & 751.188 & 980.391 \\
\hline $\mathrm{COP}$ & 2.049 & 2.041 & 2.171 & 2.093 & 2.117 & 2.085 \\
\hline $\begin{array}{l}\text { Refrigeration } \\
\text { capacity (W) }\end{array}$ & 143 & 143 & 143 & 143 & 143 & 143 \\
\hline $\begin{array}{c}\text { Mass flow } \\
(\mathrm{kg} / \mathrm{h})\end{array}$ & 2.773 & 1.452 & 1.532 & 1.479 & 1.488 & 1.840 \\
\hline $\begin{array}{c}\text { Discharge } \\
\text { temperature } \\
\left({ }^{\circ} \mathrm{C}\right)\end{array}$ & 139.5 & 134.5 & 120.2 & 128.8 & 127.0 & 126.0 \\
\hline $\begin{array}{c}\text { Capillary } \\
\text { tube inlet } \\
\text { temperature } \\
\left({ }^{\circ} \mathrm{C}\right)\end{array}$ & 32.2 & 32.2 & 32.2 & 32.2 & 32.2 & 32.2 \\
\hline $\begin{array}{l}\text { Suction } \\
\text { specific } \\
\text { volume } \\
\left(\mathrm{m}^{3} / \mathrm{kg}\right)\end{array}$ & 0.2121 & 0.2571 & 0.6894 & 0.3607 & 0.3914 & 0.2425 \\
\hline $\begin{array}{c}\text { Liquid } \\
\text { specific heat } \\
(\mathrm{kJ} / \mathrm{kgK})\end{array}$ & 1.44733 & 2.80027 & 2.49904 & 2.66510 & 2.63428 & 2.28916 \\
\hline $\begin{array}{l}\text { Liquid } \\
\text { density } \\
\left(\mathrm{kg} / \mathrm{m}^{3}\right)\end{array}$ & 1183.27 & 483.445 & 542.291 & 505.718 & 511.576 & 588.688 \\
\hline
\end{tabular}

Analyzing the Table 1 can be noted that the latent heat of vaporization (refrigeration effect) of the R290/R600a blend is about twice that of R134a. However, due to the low specific volume of R134a in the suction, the volumetric cooling capacity of the two fluids are similar.

In order to accept a working fluid as a replacement for a domestic refrigeration system, a similar volumetric cooling capacity and performance compared with the original refrigerant are required (Fatouh and El Kafafy, 2006).

The higher mass fraction of propane (R290) provides higher condensing temperatures and less evaporation temperature, which can lead to large ice formation on the evaporator. The mixture of R290/R600a (60:40) has the best solution in this regard.
The vapour densities under suction conditions for mixtures and R290 to have lower than those of $\mathrm{R} 134 \mathrm{a}$, corresponding to a lower refrigerant charging in the system relative to $\mathrm{R} 134 \mathrm{a}$.

\section{CONCLUSIONS}

The research and development efforts in the field of Refrigeration and Air-Conditioning apply to the use of natural refrigerants is not only associated with the need to preserve the environment, but also has great importance because the latent need of increased energy efficiency of equipments.

Hydrocarbons, such as liquefied petroleum gas (LPG), are environmentally friendly and are available in nature, the use of these substances as refrigerants in domestic refrigerators is very attractive. 
According to the thermodynamic analysis developed for hydrocarbon fluids may be noted that these lower levels of pressures in the condenser and evaporator.

The use of R290 and mixtures involving hydrocarbons provides a tripling of the latent heat of vaporization compared to R134a. This factor leads to a reduction of about $50 \%$ of the need to mass charge of refrigerant in the cooling system for a same capacity of the equipment.

Hydrocarbons provide lower compressor discharge temperatures, providing longer life to these components. The coefficient of performance of the system with hydrocarbons and mixtures grew by about $5 \%$ compared to R134a.

Consequently, lower compression works are required to hydrocarbons compared to $\mathrm{R} 134 \mathrm{a}$ due to thermophysical properties.

In order to consolidate the hydrocarbons and their mixtures as substitutes for synthetic fluids, such as HFC134a, the refrigeration industry should focus its efforts on developing compressors suitable for volumetric cooling capacity of natural refrigerants, and the development of new design methodologies of heat exchangers, since the mixtures behave differently from pure fluids with respect to phase change.

\section{ACKNOWLEDGEMENTS}

This research received financial support from the Federal Institute of Education, Science and Technology of Rio Grande do Norte, by Edict No. 23/2010 (Pro-Rectory of Research and Innovation).

\section{REFERENCES}

Alsaad, M. A., and Hammad, M. A., 1998, The Application of Propane/Butane Mixture for Domestic Refrigerators, Applied Thermal. Engineering, Vol. 18, pp. 911-918

Akash, B. A., and Said, S. A., 2003, Assessment of LPG as a Possible Alternative to R-12 in Domestic Refrigerators, Energy Conversion and Management, Vol. 44, pp. 381-388.

Borges, B., Melo, C., Gonçalves, J., and Hermes, C., 2010, Simulação Transiente de Refrigeradores Domésticos: Uma Abordagem Quase-Estática Semi-Empírica. Anais do VI Congresso Nacional de Engenharia Mecânica. Campina Grande - PB. Associação Brasileira de Engenharia e Ciências Mecânicas. (in Portuguese)

Fatouh, M., and El Kafafy, M., 2006, Assessment of Propane/Commercial Butane Mixtures as Possible Alternatives to $\mathrm{R} 134 \mathrm{a}$ in Domestic
Refrigerators, Energy Conversion and Management, Vol. 47, pp. 2644- 2658.

Hammad, M. A., and Alsaad, M. A., 1999, The Use of Hydrocarbon Mixtures as Refrigerants in Domestic Refrigerators, Applied Thermal Engineering, Vol. 19, pp. 1181-1189.

Kim, M. H., Lim, B. H., and Chu, E. S., 1998, The Performance Analysis af a Hydrocarbon Refrigerant R-600a in a Househould Refrigerator/Freezer, KSME International Journal, Vol.12, No.4, pp.753760.

Lee, Y. S., and Su, C. C., 2002, Experimental Studies of Isobutane (R600a) as The Refrigerant In Domestic Refrigeration System, Applied Thermal Engineering, Vol. 22, pp. 507-519.

Mohanraj, M., Jayaraj, S., and Muraleedharan, C., 2007, Improved Energy Efficiency for HFC134a Domestic Refrigerator Retrofitted with Hydrocarbon Mixture (HC290/HC600a) as Drop-in Substitute, Energy for Sustainable Development, Vol. XI, No. 4, December.

Maclaine-Cross, I. L., 1997, Why Hydrocarbons Save Energy, AIRAH Journal Vol. 51, pp. 33- 37.

Melo, C. A., and Jannuzzi, G. M., 2008, O Estoque de Refrigeradores no Brasil: Diferenças e Semelhanças Regionais por Faixas de Renda, Espaço Energia, No. 08, Abril, pp. 1807-8575. (in Portuguese)

McLinden, M. O., Klein, S. A. Lemmon, E. W., and Peskin, A. P., 1998, REFPROP, Version 6.0, NIST Properties of Refrigerants and Refrigerant Mixtures, NIST Standard Reference Database 23, U.S. Dept. of Commerce, Standard Reference Data Program, Gaithersburg, MD.

Poggi, F., Macchi-Tejeda, H., Leducq, D., and Bontemps, A., 2008, Refrigerant Charge in Refrigeration Systems and Strategies of Charge Reduction, International Journal of Refrigeration, Vol. 31, pp. 353-370.

Richardson, R. N., and Butterworth, J. S., 1995 , The Performance of Propane/Isobutane Mixtures in a Vapor Compression Refrigeration System, International Journal of Refrigeration, Vol. 18, No. 1, pp. 58-62.

Sekhar, S. J., and Lal, D. M., 2004, HFC134a/HC600a/HC290 Mixture a Retrofit for CFC12 System. International Journal of Refrigeration, Vol. 28, pp. 735-743.

Tashtoush, B., Tahat, M., and Shudeifat, M. A., 2002, Experimental Study of New Refrigerant Mixtures to Replace R12 in Domestic Refrigerators. Applied Thermal Engineering, Vol. 22, pp. 495-506.

Received: January 15,2010

Revised: February 15, 2010

Accepted: March 15, 2010 